\title{
The role of information in reducing medical error
}

\author{
Reducing error is an ongoing process, always in need of fine-tuning
}

A

crucial challenge in efforts to prevent or reduce the occurrence of medical error is obtaining information about the diverse types of medical mishaps. "Mishap" is a useful term - it is neutral and broad enough to encompass the wide range of things that can go wrong in clinical practice. The types of medical mishaps include the "near-miss", the "incorrect procedure or treatment which does not harm the patient", the "adverse event" (either anticipated or unanticipated), and, finally, the "sentinel event" (a blatant error, such as a blood transfusion error). All these forms of mishap have the potential to provide important information to help minimise or prevent patient harm and enhance standards of medical practice.

There are arguments about the definitions of medical error, and my assertion - that lessons can be learned from all forms of medical mishap — deliberately cuts a broad swath. Close examination of each of these types of mishap provides different learning opportunities.

- Near-misses, or errors that cause no harm, can trigger a re-evaluation of correct procedures to prevent these events;

- Adverse events, both "anticipated" and "unanticipated", can help clinicians develop more rigorous thinking about evidence and standards; and

- Sentinel events can show how the protective systems put in place can be breached.

Collecting extensive information in all these mishap categories not only leads to interventions to minimise and prevent harm, but also allows detection of patterns of error. For example, if an inordinate number of errors occur during night shifts, or when the change of shift occurs, organisational changes may be required. Information about mishaps also provides material for teaching medical students, residents and community practitioners, with the aim of preventing future errors. If the information prevents errors then there will be impressive cost savings for hospitals and healthcare systems, as well as for patients and their families. ${ }^{1}$ Finally, information about errors and patterns of errors forearms clinicians to avoid patient injury, thus reducing the stress involved in suspecting or knowing their actions may have caused harm.

But there remains an ongoing impediment: can healthcare data systems provide timely information for risk management and reducing medical mishaps? In the book Medical mishaps. Pieces of the puzzle contributors from several countries identified "multiple overlapping and faulty mechanisms for the revelation, investigation and mitigation of errors". There was "clearly considerable scope for greater collaboration, integration and coordination". 2 And the situation in Australia appears to be no exception. One of the key priorities of the Australian Council for Safety and Quality in Health Care (ACSQHC) is enhancing processes for measuring local quality improvement and aggregate-level reporting of performance and outcomes. ${ }^{3}$

A report in this issue of the Journal by Kingston and colleagues (page 36) ${ }^{4}$ explores the attitudes of the two main health-profes- sional protagonists involved in reporting medical error. It analyses the differential use of incident reporting by doctors and nurses, and attributes this to the different cultures of the two professions. This finding has been well substantiated. Nurses work in a culture that responds to directives, including the directive to report incidents; doctors work in a culture that values intragroup action and professional-cultural definitions of error or mistake. ${ }^{5}$

Other, systems factors also influence the decision to report incidents: time constraints, dissatisfaction with the process, inadequate feedback, and failure to value the process. ${ }^{5}$ In addition, there may be confusion about what should be reported, feelings of fear of retribution and doubts about the possibility of remediation.

Finally, what are the views of healthcare consumers? In a study published in the 7 June issue of the Journal, ${ }^{6}$ a random sample of Australians supported vigorous reporting of errors, and $68 \%$ of those surveyed also wanted disclosure of the identity of the healthcare worker involved. While this is understandable, it shows the need to educate the public about the importance of a "no-blame" culture to ensure that reports will be made in the first place. The need for a flow of information far outweighs fingerpointing. Clinicians want error reduction, and favour anonymity. Patients and the public want error reduction and are likely to accept anonymity in the name of this goal.

The ACSQHC supports the principle of "no blame", and has recently published a document Open disclosure standard: a national standard for open communication in public and private hospitals, following an adverse event in health care. This provides clear guidelines for patients, healthcare professionals and organisations confronting and dealing with medical error, and the legal issues attending such events. Its major message is an open, blame-free culture. $^{7}$

Despite the human and systems factors impeding reporting of medical error, many of these can be overcome by adequate incident-reporting systems. These have the following characteristics: ${ }^{8}$

- they are anonymous and easy to use (computerised);

- they acknowledge receipt of a report and confirm that it is being investigated;

- they report back the results of the investigation in a timely manner;

- they use the information for programs of reduction;

- they provide feedback about successful reduction efforts; and

- they receive continual public support from key physicians in leadership positions.

The process of error reduction involves long-term effort. There needs to be consistent and persistent emphasis on a cycle of attention to information, patterns revealed by information, errorreduction efforts, evaluation, more information and more reduction efforts. These efforts now also include producing informed patients, who are coached to ask the questions that might avoid errors. 


\section{EDITORIALS}

We should think about this cyclic process to reduce error as an ongoing one, always in need of fine-tuning. Its effectiveness depends on clinical leadership providing a continuing example in error reporting.

\section{Marilynn M Rosenthal} Adjunct Professor of Internal Medicine, Department of Internal Medicine, University of Michigan Medical School, Ann Arbor Michigan, USA Mmrosent@umich.edu

1 Johnson WG, Brennan TA, Newhouse JP, et al. The economic consequences of medical injuries. JAMA 1992; 267: 2487-2492.

2 Mulcahy L, Rosenthal MM. Beyond blaming and perfection: a multidimensional approach to medical mishaps. In: Rosenthal MM, Mulcahy L, Lloyd-Bostock S, editors. Medical mishaps. Pieces of the puzzle. Buckingham, UK: Open University Press, 1999: 6.
3 Australian Council for Safety and Quality in Health Care. Report to the Australian Health Ministers on Safety and Quality in the Australian Health Care Agreements. Canberra: ACSOHC, 13 Sep 2002. Available at: www.safetyandquality.org/articles/Publications/ SafetyQualityHealthReformAgenda_web.pdf (accessed Jun 2004).

4 Kingston MJ, Evans SM, Smith BJ, Berry JG. Attitudes of doctors and nurses toward incident reporting: a qualitative analysis. Med J Aust 2004; 181: 36-39.

5 Rosenthal M. The incompetent doctor: Behind closed doors. Buckingham, Philadelphia, Pa: Open University Press, 1995.

6 Evans SM, Berry JG, Smith BJ, Esterman AJ. Anonymity or transparency in reporting of medical error: a community-based survey in South Australia. Med J Aust 2004; 180: 577-580.

7 Australian Council for Safety and Quality in Health Care. Open disclosure standard: a national standard for open communication in public and private hospitals, following an adverse event in health care. Canberra: ACSQHC, Jul 2003.

8 Kohn LT, Corrigan J, Donaldson MS, editors. To err is human: building a safer health system. Washington DC: National Academy Press, 1999. 